\title{
CYTOFLUOROMETRY OF DNA IN UREDOSPORES OF PUCCINIA GRAMINIS F.SP. TRITICI
}

\author{
By P. G. WILLIAMS* AND K. W. MENDGEN \\ Institut für Pflanzenpathologie und Pflanzenschutz, Georg-August Universität, \\ Göttingen, Federal Republic of Germany
}

(With Plate 3 and 2 Text-figures)

\begin{abstract}
The nuclear DNA content of uredospores of a monokaryotic, variant strain of Puccinia graminis f.sp. tritici was determined using Feulgen fluorescence photometry. The relative values obtained when compared with haploid nuclei in uredospores of the parent dikaryotic strain, agree with the proposition that the monokaryotic variant is diploid. Mcasurements of DNA content also indicated that each nucleus in the abnormally large, binucleate uredospores formed by the variant strain, has twice as much DNA as a haploid nucleus.
\end{abstract}

A study of uredospores with the light microscope indicated that a monokaryotic, variant strain of Puccinia graminis f.sp. tritici was diploid (Williams, 1974). The investigation reported here sought to confirm this finding by measuring the deoxyribose nucleic acid (DNA) content of uredospore nuclei of the variant strain.

\section{MATERIALS AND METHODS}

\section{Rust strains}

The monokaryotic strain was obtained from Prof. I. A. Watson, Department of Agricultural Botany, University of Sydney. It is designated culture 7 I 868 in the University's collection of rust strains. As mentioned elsewhere (Williams, 1974), this strain was derived from a uredium resulting from an inoculation of wheat with mycelium of the axenic monokaryon vic (Maclean, Scott \& Tommerup, I97I). Nuclei in uredospores of culture 71868 were compared with haploid nuclei in the parent, dikaryotic strain, culture 334. Gulture 334 uredospores formed the axenic culture that produced the monokaryotic line vi (Maclean \& Scott, I970). The line VI was the parent of vic (Maclean et al. 1971). The strains were maintained on wheat seedlings (cv. Nordgau) in separate growth cabinets at $23^{\circ}$.

\section{Feulgen staining}

Staining nuclei in mature uredospores is difficult and special treatments must be used to alter the spore wall and the relative affinity for dyes of nuclei and cytoplasm (Williams, 1974). Conventional methods are success-

* Permanent address: Department of Agricultural Botany, University of Sydney, Sydney, 2006. 
ful when, after germination, the nuclei have migrated from the spore into the germ-tube. Samples of uredospores taken from single, isolated uredosori were allowed to germinate on a drop of water on a microscope slide previously smeared with egg white. Slides carried one sample each of the monokaryotic and dikaryotic strain arranged side by side in the centre and separated by a streak of petroleum jelly. Three to four hours after seeding the slides were dried and the germinated uredospores were fixed for $30 \mathrm{~min}$ in 6 vol. $96 \%$ ethyl alcohol, 3 vol. chloroform, I vol. acetic acid. After transfer to water through an alcohol series the preparations were hydrolysed $5 \mathrm{~min}$ in $4 \mathrm{~N}-\mathrm{HCl}$ at $30^{\circ}$ (the optimum conditions of hydrolysis were determined in the experiments described in Results). The slides were soaked 5 min in $\mathrm{SO}_{2}$-water and then immersed for $4 \mathrm{~h}$ in the dark in $p$-rosaniline-Schiff reagent ( $5^{\circ}$ o g $p$-rosaniline (Chroma, Stuttgart) $/ \mathrm{l} \mathrm{Io}^{-3}$ $\mathrm{N}-\mathrm{HCl}$, reduced overnight with $6 \cdot \mathrm{o} \mathrm{g} / \mathrm{l}$ sodium metabisulphite, decolorized with $\mathrm{I} \cdot \mathrm{Og} / 1$ Norit, filtered). Excess reagent was removed in four washes of $\mathrm{SO}_{2}$-water and two of distilled water. After drying in air the preparations were mounted in immersion oil (Leitz) under one coverglass and sealed with clear nail lacquer. To prevent any bleaching of the stain, the slides were kept in the dark prior to their measurements. As controls, slides were prepared in the same manner except that hydrolysis was omitted.

Fluorescent nuclei were photographed with Kodak Tri-X Pan film developed in EMOFIN (Tetenal, Hamburg).

\section{DNA measurement}

DNA content of nuclei was determined by measuring the red fluorescence of Feulgen-stained nuclei illuminated with greelı light (Kasten, Burton \& Glover, I 959). The instrument available to the investigation was equipped for dark-field illumination. This relatively simple means for fluorescence excitation proved to be adequate, although incident illumination has been recommended for fluorescence cytophotometry (Böhm \& Sprenger, I968). Measurements were made with a Leitz MPV I Microscope Photometer with variable diaphragm (Leitz, Wetzlar, Germany) (Böhm \& Sprenger, 1968). The excitation beam, originating from a highpressure $\mathrm{Hg}$ lamp, $200 \mathrm{~W}$, passed a heat filter $(2 \mathrm{~mm} \mathrm{KG} \mathrm{I,} \mathrm{Schott,}$ Mainz), the excitation filters for green excitation (4 mm BG 38 and $\mathrm{Al} 546$, both from Schott, Mainz) and the dark-field condenser D I.20 A to give a dark-field illumination. For observation, an oil-immersion objective Fl 95 N.A. I. Io and a barrier filter K 6ro (Schott, Mainz) was used. The measurement was done with a RCA I P 21 photomultiplier and a microammeter (Norma, Wien). To reduce fading when centring and focusing, the barrier filter was removed and the object was illuminated with a lowintensity tungsten lamp. For measuring, the barrier filter was put back and the excitation beam directed to the object with the help of a $45^{\circ}$ reflecting mirror. The summit reading of the ammeter was recorded and the excitation cut off again by turning the mirror. Thus, exposure to excitation light was restricted to a minimum and fluorescence fading became negligible. As no standard was used, readings of the ammeter are relative and unique for each experiment. During every experiment, instrument calibration 


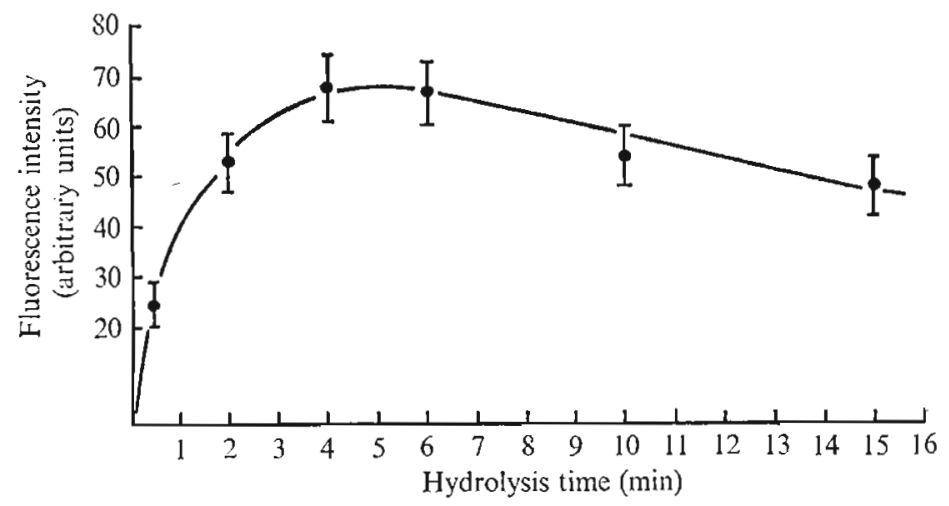

Fig. I. Feulgen fluorescence intensity (in arbitrary units) of haploid nuclei in uredospore germ-tubes of culture 334 of Puccinia graminis f.sp. tritici in relation to hydrolysis time (min) in $4 \mathrm{~N}-\mathrm{HCl}$ at $30^{\circ}$. Vertical line represents standard deviation.

(e.g. measuring diaphragm) was kept strictly constant. The fluorescence intensity of a nucleus was obtained from the difference between the reading given with the nucleus in the measuring field and that given by a field including the adjacent cytoplasm.

\section{RESULTS}

Preliminary experiments suggested that hydrolysis in I N-HCl at $60^{\circ}$ was unsuitable and hydrolysis with $4 \mathrm{~N}-\mathrm{HCl}$ at $30^{\circ}$ as used by Böhm \& Sprenger (1968) was adopted. Measurements of fluorescence intensity of haploid nuclei in germ-tubes of culture 334 showed that maximum staining was obtained after $4^{-6}$ min hydrolysis (Fig. I). Fluorescence of nuclei was only slightly increased when fixation was increased from $3^{\circ}$ min to $16 \mathrm{~h}$. Nuclei in control (unhydrolysed) preparations gave no measurable fluorescence, but a small amount of Feulgen reactive material was present in germ-tube walls before and after hydrolysis.

The stoichiometry of fluorescence intensity and DNA content was demonstrated using dikaryons in culture 334. Ammeter readings were compared when one nucleus or a pair of nuclei were within the measuring field. Ten haploid nuclei, measured separately, gave a mean value of $43 \pm 5$; the mean of five dikaryons was $89 \pm 10$, that is, about twice the value for single nuclei.

Comparisons of nuclear DNA content between the monokaryotic and the dikaryotic strain were made between the adjacent samples on each of a number of slides. The data from two slides are shown in Fig. 2. A single class of values was found in each strain. According to a $t$ test of the sample means the data fit the hypothesis that the DNA content of culture 71868 nuclei (Pl. 3, fig. I) is double that of haploid nuclei in culture 334 (Pl. 3 , fig. 2). (Because of dissimilar variances the modified $t$ test of Cochrane \& Cox (1957) was used for the data from slide 2.) This result agrees with the previous observations of comparative size of uredospores and their nuclei 
Slide I

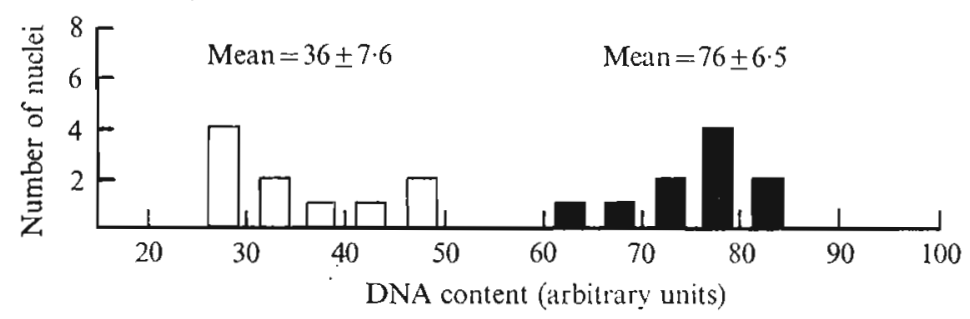

Slide 2

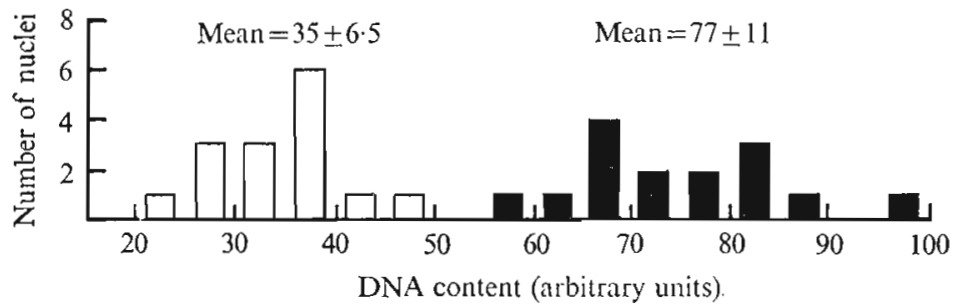

Fig. 2. Frequency distribution of DNA content (arbitrary units) of germ-tube nuclei in dikaryotic (culture 334, open bars) and monokaryotic (culture 71868, shaded bars) strains of Puccinia graminis f.sp. tritici.

Table I. DNA content in arbitrary units (mean \pm standard deviation) of nuclei in normal, uninucleate and large, binucleate uredospores formed by the monokaryotic culture $7 \mathrm{I} 868$ of $\mathrm{P}$. graminis $f . s p$. triitici

\section{Number of uredospores measured}

8

\section{Uninucleate uredospores}

$49 \pm 7^{\circ} \circ$

\section{Binucleate uredospores}

$4^{8} \pm 12$

(Williams, I974) indicating that uredial cultures derived from the axenic monokaryon vic of Maclean et al. (I971) are diploid.

The monokaryotic culture 7 I 868 forms small numbers of abnormally large uredospores, most of which contain two large nuclei (Williams, I 974). The measurements of fluorescence given in Table I show that each nucleus in the germ-tube of a binucleate uredospore ( $\mathrm{Pl}$. 3, fig. 3) has the same DNA content as the single nucleus in a normal-sized uredospore of this strain, thus demonstrating that the large uredospores contain two diploid nuclei.

\section{DISCUSSION}

The DNA values of germ-tube nuclei comprised single classes presumably representing i $\mathrm{C}$ and $2 \mathrm{C}$ or ${ }_{2} \mathrm{C}$ and ${ }_{4} \mathrm{C}$ levels for haploid and diploid nuclei respectively. No information was obtained to discriminate between these alternative possibilities. However, a recent investigation of nucleic 
acid synthesis in Uromyces fabae (Pers.) Wint. sporelings (Staples, 1974) indicated that an $\mathrm{S}$ phase precedes the nuclear division associated with appressorium formation in this rust fungus (Maheshwari, Hildebrandt \& Allen, 1967 ). In Uromyces it appears that the uredospore nuclei are in $\mathrm{G}_{\mathbf{1}}$ and remain in that state in the absence of a stimulus leading to the differentiation of an infection structure. If the same situation holds in Puccinia graminis - that is, that germ-tube nuclei are in $\mathrm{G}_{1}$ of the cell cycle - the DNA values we observed represent $\mathrm{I} C$ and $2 \mathrm{C}$ levels.

The DNA content of fungal nuclei has previously been determined by absorption photometry of DNA (Bryant \& Howard, 1969). The results of our experiments show that the relative amount of DNA in fungal nuclei can also be measured by fluorescence photometry using dark-field illumination, a simpler method and one requiring relatively inexpensive equipment.

Our results confirm the work of Williams \& Hartley (I97I), who first obtained evidence that Puccinia graminis f.sp. tritici can exist as a somatic diploid. The techniques we have used will be useful in exploring the possible significance of this discovery in relation to asexual variation in this pathogen.

We are grateful to the Wheat Industry Research Council of Australia and the Alexander von Humboldt Foundation for financial support to one of us (P.G.W.) and to Dr D. J. Maclean for helpful criticism of the manuscript.

\section{REFERENCES}

Böhm, N. \& Sprenger, E. (1968). Fluorescent cytophotometry: A valuable method for the quantitative determination of nuclear Feulgen-DNA. Histochemie 16, 1 00-1 18.

Bryant, T. R. \& Howard, K. L. (1969). Meiosis in the Oömycetes: I. A microspectrophotometric analysis of deoxyribonucleic acid in Saprolengnia terrestris. American Journal of Bolany 56, 1075-1083.

Cochrane, W. G. \& Cox, G. M. (1957). Experimental designs, 2nd ed. New York: John Wiley \& Sons.

Kasten, F. H., Burton, V. \& Glover, P. (1959). Fluorescent Schiff-type reagents for cytochemical detection of polyaldehyde moieties in sections and smears. Nature, London 184, I 797-I 798.

MAaclean, D. J. \& SCOTT, K. J. (I970). Variant forms of saprophytic mycelium grown from uredospores of Puccinia graminis f.sp. tritici. Journal of General Microbiology 64, 19-27.

Maclean, D. J., ScotT, K. J. \& Tommerup, I. G. (1971). A uninucleate wheat-infecting strain of the stem rust fungus isolated from axenic cultures. Fournal of General Microbiology $65,339-342$.

Maheshwari, R., Hildebrandt, A. C. \& Allen, P. J. (1967). The cytology of infection structure development in uredospore germ tubes in Uromyces phaseoli var. typica (Pers.) Wint. Canadian Journal of Botany 45, 447-450.

STAPLES, R. C. (1 974). Synthesis of DNA during differentiation of bean rust uredospores. Physiological Plant Pathology (in the Press).

Wrlliams, P. G. (1974). Evidence for diploidy of a monokaryotic strain of Puccinia graminis f.sp. tritici. Transactions of the British Mycological Society (in the Press).

WiLlisms, P. G. \& HARTLEY, M. J. (I971). Occurrence of diploid lines of Puccinia graminis tritici in axenic culture. Nature New Biology 229, I8I-182. 
EXPLANATION OF PLATE 3

Red fluorescence of Feulgen-stained nuclei in germ-tubes of Puccinia graminis f.sp. tritici uredospores.

Fig. I. Culture 71868, uninucleate. $\times$ I 100.

Fig. 2. Culture 334. $\times$ i 100 .

Fig. 3. Culture 71868 , binucleate. $\times 1100$.

(Accepted for publication 19 June 1974) 
Plate 3

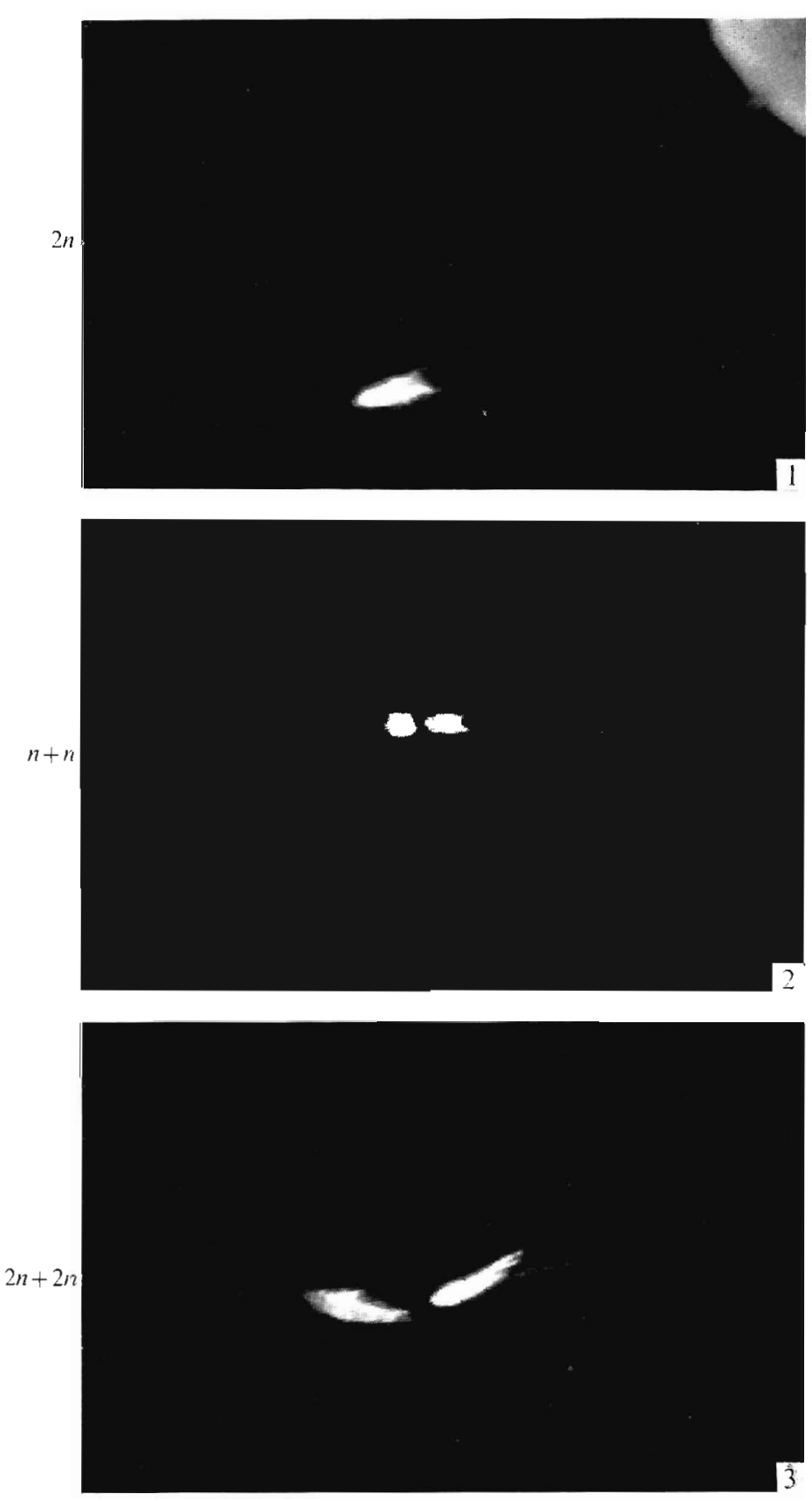

(Facing p. 28) 